\title{
Gastrointestinal Stromal Tumors with Internal Tandem Duplications in 3' End of KIT Juxtamembrane Domain Occur Predominantly in Stomach and Generally Seem to Have a Favorable Course
}

Jerzy Lasota, M.D., Agnieszka Dansonka-Mieszkowska, M.S., Tomasz Stachura, M.D., Regine Schneider-Stock, Ph.D., Markku Kallajoki, M.D., Sonja E. Steigen, M.D., Maarit Sarlomo-Rikala, M.D., Carsten Boltze, M.D., Radzislaw Kordek, M.D., Albert Roessner, M.D., Jerzy Stachura, M.D., Markku Miettinen, M.D.

Department of Soft Tissue Pathology, Armed Forces Institute of Pathology, Washington, DC (JL, AD-M, MM); Departments of Surgery (TS) and of Pathomorphology (JS), Jagiellonian University, Krakow, Poland; Department of Pathology, Otto-von-Guericke University, Magdeburg, Germany (RS-S, CB, AR); Laboratory of Pathology, Turku University Hospital, Turku, Finland (MK); Department of Pathology, University Hospital of Tromsoe, Norway (SES); Department of Pathology, Haartman Institute of the University of Helsinki, Helsinki, Finland (MS-R); Chair of Oncology, Medical University of Lodz, Lodz, Poland (RK); and Department of Molecular Pathology, Maria Sklodowska-Curie Memorial Cancer Institute, Warsaw, Poland $(A D-M)$

Gastrointestinal stromal tumors (GISTs) are the most common mesenchymal tumors of the gastrointestinal tract. GISTs express KIT and have KIT mutations. Majority of these mutations cluster in the 5 ' end of the KIT juxtamembrane domain. Little is known about the clinicopathological profile of GIST carrying internal tandem duplications in the 3' end of KIT juxtamembrane domain (ITDs in the 3' KIT-JM). In this study, 500 immunohistochemically KIT-positive GISTs were screened for this type of mutation, and 18 cases were identified (3.6\%). The majority of the ITDs consisted of 1 to 18 codon duplications, with $\mathrm{Tyr}^{578}$, Asp $^{579}$, and Leu ${ }^{576}$ being the most commonly duplicated codons. There were 14 gastric (78\%), 2 small intestinal (11\%), and 2 anal (11\%) primary tumors diagnosed in 12 females and 6 males with median age of 71 years. The frequency of IDTs in gastric GISTs was $6.5 \%$ and was only $0.5 \%$

Copyright (C) 2003 by The United States and Canadian Academy of Pathology, Inc.

VOL. 16, NO. 12, P. 1257, 2003 Printed in the U.S.A.

Date of acceptance: August 15, 2003.

Partially supported by the American Registry of Pathology and by the grant from the Polish Committee for Scientific Research (3 PO5C 059 25).

$\mathrm{AD}-\mathrm{M}$ is a research fellow at the Department of Soft Tissue Pathology, AFIP, Washington DC.

The opinions and assertions contained herein are the expressed views of the authors and are not to be construed as official or as reflecting the views of the Departments of the Army or Defense.

Address reprint requests to: Jerzy Lasota, M.D., Department of Soft Tissue Pathology, Armed Forces Institute of Pathology, 14th Street and Alaska Avenue, N.W., Washington, DC 20306-6000; fax: 202-782-9182; e-mail: lasota@afip.osd.mil.

DOI: $10.1097 / 01 . M P .0000097365 .72526 .3 E$ in intestinal GISTs. There was a strong female predominance $(79 \%)$ among the patients with gastric tumors. Histologically, 16 GISTs were spindle cell, and 2 had epithelioid morphology. The sizes of primary tumors varied from 1 to $>20 \mathrm{~cm}$. Based on the combination of tumor size and mitotic activity, six tumors were classified as benign or probably benign, eight as having uncertain malignant potential, and only four as malignant. Follow-up data available in 17 patients confirmed the malignant course of disease in 3 cases. Only one of the tumors classified as potentially malignant metastasized, although the follow-up was limited in some cases. In summary, the great majority of GISTs with ITDs in the 3' KIT-JM were mitotically inactive tumors occurring predominantly in the stomach and that seemed to have a favorable course. This suggests that presence of these IDTs may define a clinicopathologically favorable subset of GISTs. The consequence of these mutations to KIT signaling should be investigated.

KEY WORDS: C-kit, GIST, Mutations.

Mod Pathol 2003;16(12):1257-1264

Gastrointestinal stromal tumors (GISTs) are currently defined as KIT-positive mesenchymal tumors of the gastrointestinal (GI) tract showing spindle cell, epithelioid, and occasionally, pleomorphic morphology (1). KIT-expressing interstitial cells of Cajal or related stem cells are believed to be GIST progenitor cells $(2,3)$. Interstitial cells of Cajal form 
the networks within gut wall and participate in the generation of pacemaker activity that is necessary to maintain the peristaltic motor activity of the gut and regulate the neurotransmission (4-8).

KIT gene is a member of the Type III receptor tyrosine kinase gene family and encodes a receptor for a growth factor termed stem cell factor. Activation of KIT by its ligand stem cell factor is critical for the proliferation, migration, and survival of several cell types, including interstitial cell of Cajal (9-12). KIT is also constitutionally expressed in germ cells, hematopoietic stem cells, mast cells, melanocytes, and some epithelial cells (13-15).

KIT mutations have been reported in hematopoietic malignancies including mastocytosis (16), acute myelogenous leukemia (17), myeloproliferative disorders (18), sinonasal NK/T-cell lymphomas (19), and in seminomas $(20,21)$ and GISTs (22-29).

In GISTs, gain-of-function KIT mutations were first reported in the 5 ' end of KIT juxtamembrane domain (exon 11). These mutations have been shown to lead into ligand-independent activation (phosphorylation) of KIT tyrosine kinase and to have a transforming effect in vitro (22). Subsequently, other alternative mutational "hotspots" in KIT extracellular (exon 9) and kinase (exon 13 and 17) domains have been identified in the GISTs that are negative for the exon 11 mutation (27-29).

Mutations in the KIT juxtamembrane domain (KIT-JM) in GISTs represent a heterogeneous group of deletions, missense mutations, and internal tandem duplications (ITDs) and cluster in its 5' end between Lys (550) and Glu (561) (1). However, mutations affecting the 3 ' end of KIT-JM have been rarely reported $(25,29-31)$.

An adverse prognostic significance of KIT mutations in GISTs was shown by several studies $(23,24$, 26 ), and more recently, a type of KIT mutation was suggested to be an independent prognostic marker (32). Also a possible association between ITD of Ala (502)-Tyr (503) in KIT exon 9 and malignant clinical outcome has been documented in intestinal GISTs (28).

Little is known about GISTs with ITDs in the 3' end of KIT-JM. The purpose of this study was to delineate the frequency, clinicopathologic features, and natural history of these tumors and to determine whether ITD in the 3' end of KIT-JM can define a specific clinicopathologic subset of GISTs.

Apparent success of the KIT tyrosine kinase inhibitor Imatinib (Gleevec; Novartis Pharma, Basel, Switzerland) has been reported in the treatment of metastatic and inoperable GISTs, and its potential use as neoadjuvant treatment has been discussed (33). This also makes it important to delineate the natural history of GISTs to allow for proper patient selection for enrollment in this new treatment.

\section{MATERIALS AND METHODS}

\section{Tissue Material}

Five-hundred GISTs were obtained from the files of the Armed Forces Institute of Pathology in Washington D.C., Haartman Institute of the University of Helsinki in Finland, Department of Pathomorphology of the Jagiellonian University in Krakow in Poland, Department of Pathology of Otto-vonGuericke University in Magdeburg in Germany, Department of Pathology, University Hospital of Tromsoe, Norway, and from the Chair of Oncology of the Medical University of Lodz in Poland. Expression of KIT (CD 117), CD34, $\alpha$-smooth muscle actin (SMA), desmin (DES), and S100 protein was evaluated immunohistochemically as described elsewhere (30).

The 500 GISTs included 215 tumors from the stomach, 198 from the small intestine, 44 from rectum and anus, 32 from colon, and 11 from the esophagus. Tumor size and mitotic activity were used to evaluate the likelihood of malignant behavior. Based on previously published criteria $(1,30)$ GISTs were classified into 6 groups (Table 1). Tumors assigned to Groups 1 and 2 were considered to be benign or probably benign, whereas tumors in Groups 3, 5, and 6 represented GISTs with uncertain or malignant potential.

None of the patients had been treated with Gleevec at any time during the disease.

\section{Molecular Genetic Studies}

DNA was extracted from 50 frozen tumor samples and from 450 formalin-fixed, paraffin-embedded tumor tissue blocks. Mutational status of KIT exon 11 was evaluated by PCR amplification and direct sequencing as previously described (28). In all GISTs carrying mutations in exon 11, KIT exons 9, 13 , and 17 were screened for mutations using previously described methods based on PCR amplification and direct sequencing $(28,34)$. In addition, PCR products that were negative for ITDs in direct sequencing of exon 11 were analyzed using capillary gel electrophoresis (Gene Analyzer 310; Applied biosystems, Foster City, CA).

\begin{tabular}{|c|c|c|c|}
\hline Group & Size (in $\mathrm{cm}$ ) & $\begin{array}{c}\text { Mitosis (per } \\
50 \mathrm{HPF} \text { ) }\end{array}$ & Predicted Clinical Behavior \\
\hline 1 & $\leq 2$ & $\leq 5$ & Benign \\
\hline 2 & $>2$ but $\leq 5$ & $\leq 5$ & Probably benign \\
\hline 3 & $>5$ & $\leq 5$ & Uncertain malignant potential \\
\hline 4 & $\leq 2$ & $>5$ & Malignant \\
\hline 5 & $>2$ but $\leq 5$ & $>5$ & Malignant \\
\hline 6 & $>5$ & $>5$ & Malignant \\
\hline
\end{tabular}




\section{RESULTS}

\section{Evaluation of KIT Mutation}

Eighteen (3.6\%) of 500 analyzed GISTs revealed ITDs in the 3' KIT-JM. In all but one case, ITDs were identified after PCR amplification of partially degraded DNA extracted from FFPE tissues. KIT ITD genomic and predicted amino acid sequences are shown in Figure 1. Fifteen of these mutations were perfect 1 - to 18-codon ITDs. However, in 3 cases the ITDs resulted in duplications and missense mutations of KIT. Tyr ${ }^{578}$, Asp ${ }^{579}$, and Leu ${ }^{576}$ were the most commonly duplicated codons. None of GISTs with this type of ITDs revealed other mutations in KIT exons 9, 11, 13, and 17.

\section{Demographic and Clinical Features}

The demographic and clinicopathological data of the 18 cases are summarized in Table 2 . There were 12 female and 6 male patients. There was female predominance, 11 of $14(79 \%)$, among the patients with gastric GISTs. The patient age ranged from 48 to 86 years (median 71, mean $67 \mathrm{y}$ ).

Fourteen tumors were gastric, two were small intestinal, and two were anal. The highest frequency of ITD mutation was seen in gastric and anorectal GISTs, $6.5 \%$ and $4.5 \%$, respectively. It was only $0.5 \%$ in small intestinal and $1.5 \%$ in all intestinal GISTs.

\section{Pathologic Features}

Histologically, 16 tumors had a spindle cell pattern. Although there was some morphologic heterogeneity, the gastric spindle cell GISTs often showed stromal hyalinization, and one tumor had calcifications. Of the two tumors with epithelioid pattern, one was gastric and another was small intestinal; both epithelioid tumors were highly cellular and mitotically active. The histologic spectrum of the tumors is shown in Fig. 2A-H.

The tumor sizes varied from $1 \mathrm{~cm}$ to $>20 \mathrm{~cm}$, with the majority of tumors (12 cases) being $>5 \mathrm{~cm}$. In general, the mitotic activity was low, with only 5 tumors showing $>5$ mitosis per 50 high-power fields.

Immunohistochemically all tumors were verified as KIT positive. Fifteen tumors studied were positive for CD34, but none of them were positive for smooth muscle actin, desmin, or S100 protein.

\section{Malignancy and Clinical Course of the Disease}

Based on previously published criteria, including tumor size and mitotic activity (1, 30), GISTs were

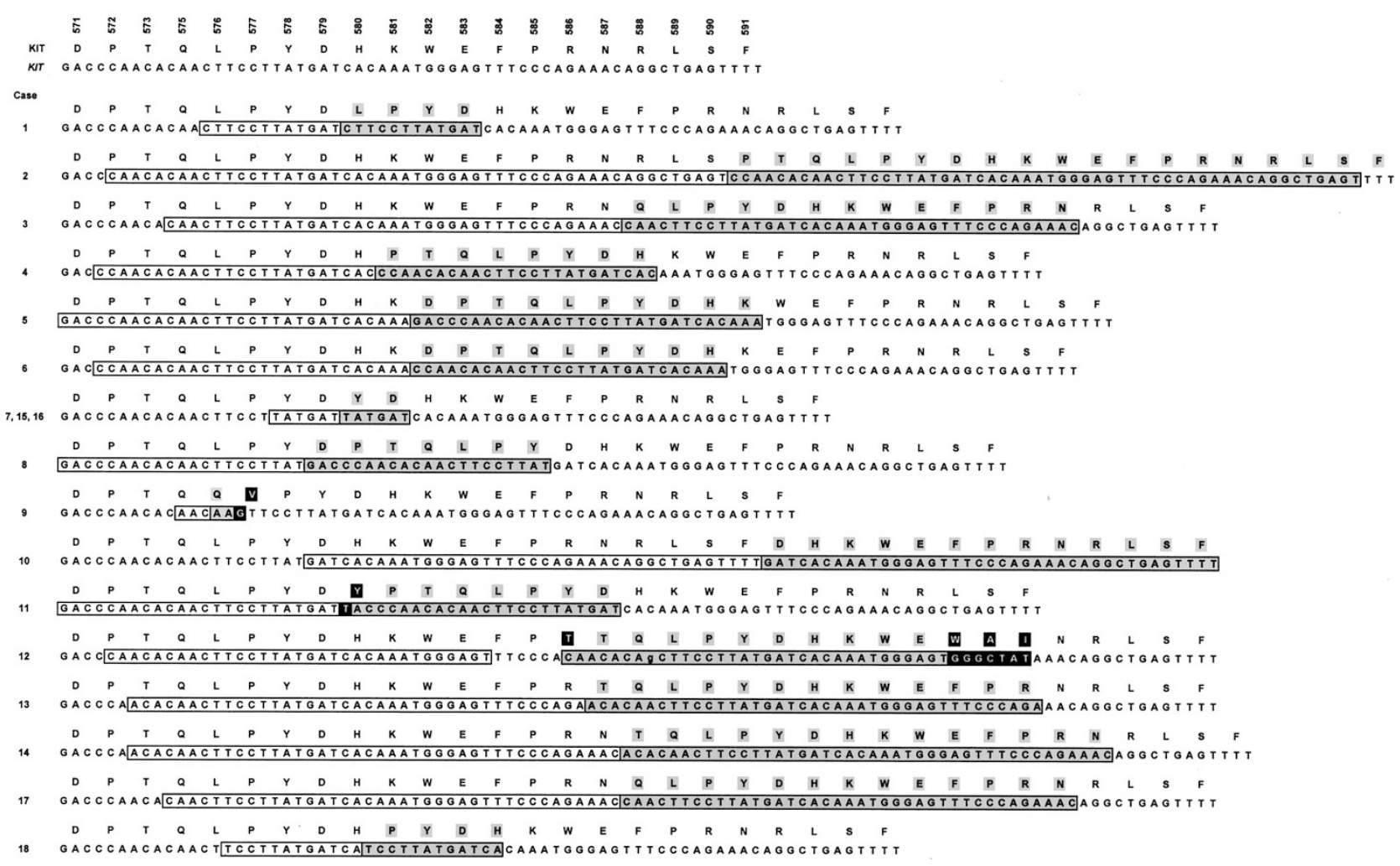

FIGURE 1. Genomic sequences of mutated KIT alleles PCR amplified from GISTs and predicted amino acid sequences of mutant KIT proteins. IDTs and missense mutations are marked as clear/gray and black boxes, respectively. Silent mutation in case 12 is indicated by a lowercase character. Part of the genomic and amino acid sequence of KIT juxtamembrane domain are shown above. Codons are numbered. 

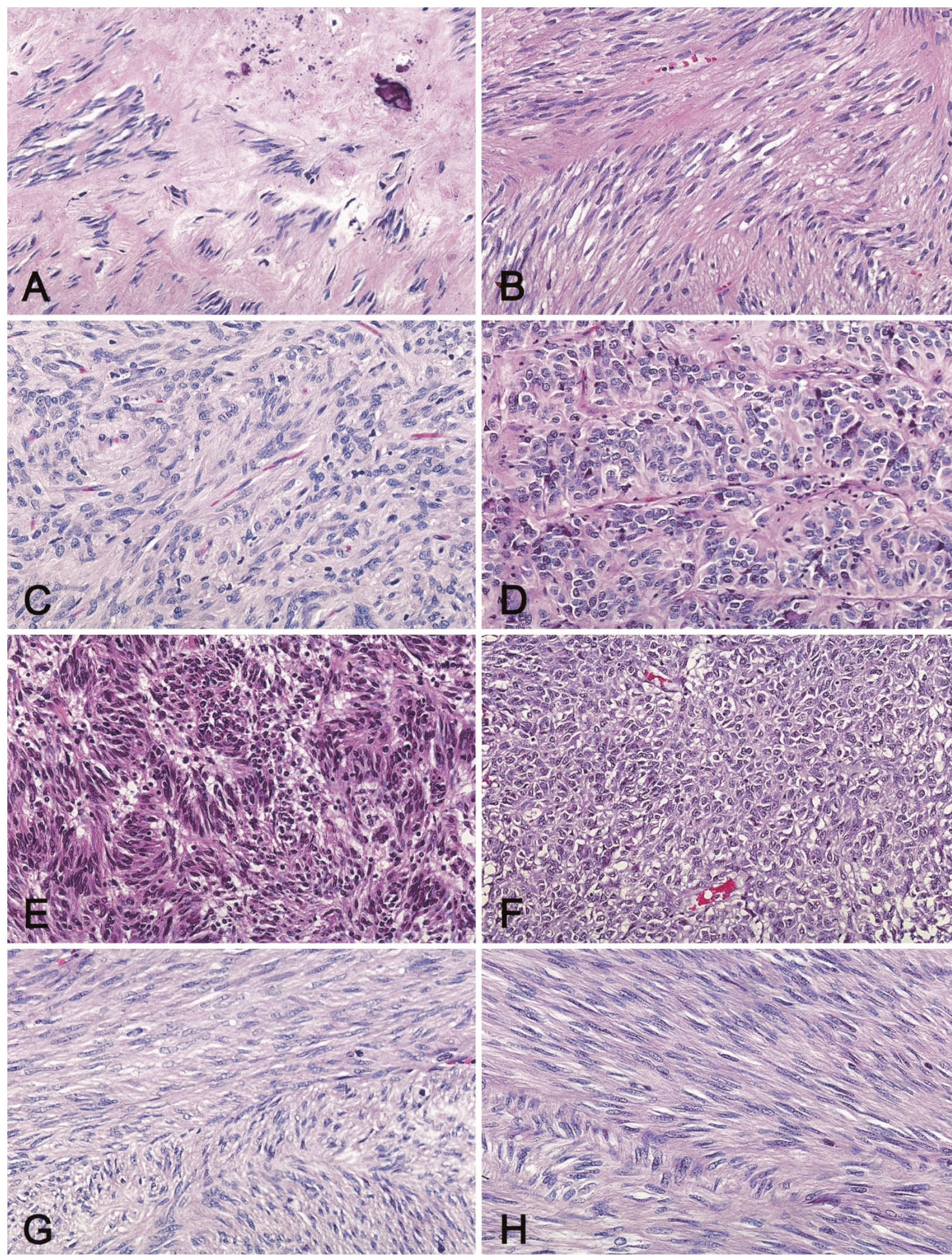

FIGURE 2. Histological features of GISTs with ITDs in the 3' KIT-JM. A, gastric GISTs with low cellularity, hyalinization and focal calcification (Case 1). B, gastric GIST with focal collagen deposition and vague nuclear palisading (Case 3). C, a more highly cellular gastric GIST with a spindle cell pattern (Case 4). D, a gastric GIST with epithelioid cytology and high cellularity (Case 11). E, a highly cellular small intestinal GIST with nuclear palisading (Case 15). F, epithelioid GIST of small intestine (Case 16). G, H, two examples of histologically similar anal GISTs with a spindle cell pattern (Cases 17 and 18). 
divided into groups according to the predicted likelihood of clinical malignancy (Table 2). Six cases were classified as benign or probably benign, eight as having an uncertain malignant potential, and four as malignant.

Clinical follow-up available in five of six cases assigned to Groups 1 and 2 verified no disease progression in these patients. One patient with incidentally found small gastric GIST died of gastric adenocarcinoma, whereas four others showed no evidence of disease for 51 to 175 months after the primary surgery.

Only one of eight patients with GISTs assigned to Group 3 with predicted malignant behavior died of disease in 59 months. Of the remaining four patients with GISTs assigned to Group 6 (malignant tumors), two had hepatic or intraabdominal metastases at the time of the primary surgery.

\section{Clinicopathologic Profiles of GISTs with ITDs and Other Types of KIT Mutations}

Distribution of primary site of 18 GISTs with ITDs and 20 GISTs with deletions (DEL) or point mutations (PM) in the 3' KIT-JM has been compared as summarized in Table 3. ITDs in gastric tumors were more common than DEL or PM in the 3' KIT-JM (6.5\% versus $3.3 \%)$.

Tumor size, mitotic activity, and metastatic disease at the primary surgery are clinicopathologic parameters that are important in the evaluation of tumor malignancy. These parameters and follow-up data of 14 gastric tumors with ITDs in the 3' KIT-JM and 50 randomly selected gastric GISTs with DEL in KIT-JM were compared. Summary of the results is shown in Table 4. An average tumor
TABLE 3. Primary Site Distribution of GISTs with ITDs and GISTs with DELsor PMs in the 3' KIT-JM

\begin{tabular}{lrcc}
\hline \multicolumn{1}{c}{ Primary Site } & All GISTs & $\begin{array}{c}\text { GISTs with ITDs } \\
\text { in the 3' KIT-JM }\end{array}$ & $\begin{array}{c}\text { GISTs with DEL or PM } \\
\text { in the 3' KIT-JM }\end{array}$ \\
\hline Esophagus & 11 & 0 & $3(27.3 \%)$ \\
Stomach & 215 & $14(6.5 \%)$ & $7(3.3 \%)$ \\
Small intestine & 198 & $2(0.5 \%)$ & $8(4 \%)$ \\
Colon & 32 & 0 & 0 \\
Rectum and anus & 44 & $2(4.5 \%)$ & $2(4.5 \%)$ \\
All intestinal & 274 & $4(1.5 \%)$ & $10(3.6 \%)$ \\
All tumors & 500 & $18(3.6 \%)$ & $20(4 \%)$ \\
\hline
\end{tabular}

size was similar in both groups; however, an average mitotic count was almost eight times higher in gastric GISTs defined by KIT-JM DELs than in those defined by ITDs. The dissemination at the primary surgery was seen two times more often in gastric GISTs with DELs than in those with ITDs. Also, metastatic disease or disease-related death was reported in $36 \%$ of gastric GISTs with DELs compared with $8 \%$ of ITD-positive tumors.

\section{DISCUSSION}

KIT mutations clustering in the area between Lys $^{550}$ and $\mathrm{Glu}^{561}$ in the $5^{1}$ end of KIT juxtamembrane domain (KIT-JM) have been documented in the majority of GISTs (1). In-frame deletions, missense mutations, and ITDs affecting 3 '-end of KIT-JM have also been reported in isolated cases $(25,29-31)$. However, little is known about the clinicopathological profile of GIST carrying these types of KIT mutations.

In this study, we screened 500 GISTs for KIT mutations and identified 18 tumors (3.6\%) with ITDs in the 3' KIT-JM in a series composed of GISTs

TABLE 2. Demographic and Clinicopathological Data of 18 GISTs with ITDs in the $3^{\prime}$ UMP uncertain malignant potential. KIT Juxtamembrane Domain

\begin{tabular}{|c|c|c|c|c|c|c|c|c|c|}
\hline Case\# & Age & Sex & Location & Size (in $\mathrm{cm}$ ) & $\begin{array}{l}\text { Mitosis } \\
\text { (per } \\
50 \mathrm{HPF})\end{array}$ & $\begin{array}{l}\text { Predicted Behavior } \\
\text { (Group) }\end{array}$ & Histology & $\begin{array}{l}\text { Follow-up } \\
\text { (in months) }\end{array}$ & Other Cancer \\
\hline 1 & 78 & $\mathrm{~F}$ & Stomach & $1 \times 0.5$ & 0 & Benign (1) & Spindle & DURC 24 & Gastric ca \\
\hline 2 & 79 & $\mathrm{~F}$ & Stomach & 2 & 0 & Benign (1) & Spindle & NED 121 & \\
\hline 3 & 69 & M & Stomach & $3 \times 3 \times 2.5$ & 0 & Benign (2) & Spindle & NED 60 & \\
\hline 4 & 72 & $\mathrm{~F}$ & Stomach & $3.5 \times 2.5 \times 1.5$ & 0 & Benign (2) & Spindle & NA & \\
\hline 5 & 86 & M & Stomach & $3.8 \times 2$ & 2 & Benign (2) & Spindle & NED 51 & Colon ca \\
\hline 6 & 58 & $\mathrm{~F}$ & Stomach & 6 & 0 & UMP (3) & Spindle & NED 9 & \\
\hline 7 & 46 & $\mathrm{~F}$ & Stomach & 7.5 & 1 & UMP (3) & Spindle & NED 6 & \\
\hline 8 & 73 & $\mathrm{~F}$ & Stomach & $9 \times 6.5 \times 5.5$ & 1 & UMP (3) & Spindle & NED 48 & \\
\hline 9 & 67 & $\mathrm{~F}$ & Stomach & 9 & 4 & UMP (3) & Spindle & NED 4 & \\
\hline 10 & 57 & M & Stomach & $10 \times 4.5 \times 4$ & 2 & UMP (3) & Spindle & NED 30 & \\
\hline 11 & 74 & $\mathrm{~F}$ & Stomach & $10 \times 7$ & 7 & Malignant (6) & Epithelioid & DUKC 26 & \\
\hline 12 & 49 & $\mathrm{~F}$ & Stomach & $16 \times 11$ & 1 & UMP (3) & Spindle & NED 192 & \\
\hline 13 & 80 & $\mathrm{~F}$ & Stomach & $22 \times 16 \times 8$ & 30 & Malignant (6) & Spindle & Liver MET & \\
\hline 14 & 58 & $\mathrm{~F}$ & Stomach & 26 and 20 & 0 & UMP (3) & Spindle & NED 14 & \\
\hline 15 & 77 & M & Small bowel & 12 & 34 & Malignant (6) & Spindle & NED 14 & \\
\hline 16 & 73 & $\mathrm{~F}$ & Small bowel & $12 \times 9 \times 8$ & 24 & Malignant (6) & Epithelioid & IA MET & \\
\hline $17^{*}$ & 59 & M & Anus & $2.2 \times 1$ & 0 & Benign (2) & Spindle & NED 175 & \\
\hline 18 & 48 & $\mathrm{M}$ & Anus & 8 & 5 & UMP (3) & Spindle & DOD 59 & \\
\hline
\end{tabular}

* Previously reported (30).

DOD died of disease, DUKC died of unknown causes, DURC died of unrelated causes, IA intraabdominal, MET metastasis, NED no evidence of disease, UMP uncertain malignant potential. 
Tabela 4. Comparison of Clinicopathological Features of Gastric GISTs with ITDs in the 3' KIT-JM and Gastric GISTs with DEL in KIT-JM

\begin{tabular}{|c|c|c|c|c|c|c|}
\hline Gastric GISTs & $\begin{array}{l}\text { Number } \\
\text { of } \\
\text { Tumors }\end{array}$ & $\begin{array}{l}\text { Average } \\
\text { Size }\end{array}$ & $\begin{array}{c}\text { Average Number } \\
\text { of Mitosis per } 50 \\
\text { HPF }\end{array}$ & $\begin{array}{l}\text { Metastasis at } \\
\text { Presentation }\end{array}$ & $\begin{array}{l}\text { Average Follow-Up } \\
\quad \text { (in months) }\end{array}$ & $\begin{array}{l}\text { Metastatic Disease } \\
\text { or Died of Disease }\end{array}$ \\
\hline With DEL in KIT-JM & 50 & $9.2 \mathrm{~cm}$ & 23 & $7(14 \%)$ & 46 based on 34 cases & 13 of $36(36 \%)$ \\
\hline With ITDs in $3^{\prime}$ KIT-JM & 14 & $9.6 \mathrm{~cm}$ & 3 & $1(7 \%)$ & 49 based on 12 cases & 1 of $13(8 \%)$ \\
\hline
\end{tabular}

of different sites. A recent study based on freshfrozen tissue reported such ITDs in 3 of $48(6 \%)$ of the analyzed GISTs (29). However, three Japanese studies using molecular techniques similar to ours failed to detect large ITDs in 294 GISTs, including 137 gastric tumors $(26,35,36)$. This could be related to ethnic and other differences between Western and Japanese populations. Other factors besides ethnicity that are causative of the apparent difference in ITD frequency in GISTs include selection and composition of study populations in relation to tumor site and technical limitations, which can potentially influence the rate of ITD detection.

Suboptimal PCR amplification of DNA template obtained from FFPE tissues can artificially decrease detection of insertion mutation. In a case of ITDs in KIT, partially or severely degraded DNA template may cause preferential amplification of the wildtype KIT at the expense of the longer mutant KIT and lead to false-negative results, particularly if PCR products are evaluated only by direct sequencing. However in this study, we have not noticed any substantial difference between ITD frequency in frozen and fixed tumors. Theoretically, some of the ITDs in the 3' KIT-JM in human GISTs could include intron 11 and exon 12 sequences, as described in canine mast cell tumors (37). The identification of such mutations would require PCR amplification of relatively large DNA or cDNA fragments using primers flanking exons 11 and 12 .

In this study, we have reported female predominance among gastric GIST patients with ITDs in the 3' KIT-JM (79\%). According to the large clinicopathological studies on GISTs, there is no clear sex predilection (1). However, the observed female predominance in our group may be related to the older age of the patients (median age, $71 \mathrm{y}$ in this study). In our experience, GIST patients older than 70 years have 1.5:1 female predominance (Miettinen et al., unpublished observations).

The current study is based on a large group of GISTs from different locations, allowing us to determine site-specific frequency of ITDs in the 3' KIT-JM. This frequency was $6.5 \%$ for gastric tumors, but only $0.5 \%$ for small intestinal tumors, suggesting marked gastric predilection. Our site-specific frequencies cannot be compared with the previously published data $(25,29,31)$, because sites were not given for tumors with such mutations (Table 5). All rectal GISTs were negative for such mutations, except two from the anal sphincter, a rare site for GIST, represented only by four cases in a previous study of 132 rectal GISTs (30). Further investigation is warranted to explore the possibility that anal GISTs represent a molecular genetic subset of rectal GISTs.

An nonrandom association between tumor location and type of KIT mutation could result from the site-related differences of interstitial cells of Cajal, the probable GIST progenitor cells. There are different subclasses of Cajal cells and their distribution in the GI tract varies $(3,4,38,39)$. Also, the susceptibility to a specific genetic alterations and ability to correct could vary between the different subsets of Cajal cells. Uniform immunophenotype in the studied tumors, namely KIT,+ CD34+, smooth muscle actin-, also raise the possibility of special subset of ancestor cells, possibly those Cajal cells that coexpress KIT and CD34 $(38,39)$.

The 18 cases with ITDs in the 3' KIT-JM, represented a morphologically somewhat heterogeneous group, although in the case of gastric GISTs, a tendency toward low mitotic rate, lower cellularity, and hyalinization was observed; this could result from a lesser proliferative capacity of tumors with these mutations.

TABLE 5. Seven ITDs in the 3' KIT-JM Previously Reported in GISTs

\begin{tabular}{|c|c|c|c|}
\hline Reference (Ref. Number) & Number of GISTs & $\begin{array}{c}\text { Number of GISTs } \\
\text { with ITD in 3' } \\
\text { KIT-JM }\end{array}$ & $\begin{array}{c}\text { Duplicated } \\
\text { KIT } \\
\text { Codons }\end{array}$ \\
\hline Moskaluk et al. (25) & 42 & $1(2.4 \%)$ & $575-586$ \\
\hline Miettinen et al. (30) & $29^{*}$ & $1(3.5 \%)$ & $577-580$ \\
\hline Rubin et al. (29) & 48 & $3(6.3 \%)$ & $\begin{array}{l}576-584 \\
572-588\end{array}$ \\
\hline Wardelmann et al. (31) & 36 & $2(5.6 \%)$ & $\begin{array}{l}575-576 \\
584-591\end{array}$ \\
\hline
\end{tabular}

* 28 rectal and one anal GIST. 
Adverse prognostic significance and correlation with malignancy of KIT mutations was initially suggested, and in some studies, KIT mutations were found to be a statistically significant adverse prognostic factor $(23,24,26)$. Also, in canine gastrointestinal mast cell tumors, a significant association between KIT mutations and higher tumor grade was reported (40). More recently, different types of KIT mutations were suggested to have different prognostic significance. Specifically, a significantly longer recurrence-free survival was shown for tumors with missense mutations than those with other types of KIT mutations including ITD in exon 9 and 11, deletions in exon 11 and point mutations in exons 13 and 17 (32). Although specific ITDs of Ala(502)-Tyr(503) in extracellular domain were previously suggested to define a malignant subset of intestinal GISTs (28), more heterogeneous ITDs in 3' KIT-JM may play the opposite role in gastric GISTs.

The present study suggests that the ITDs in the 3' KIT-JM may identify a clinically more favorable subset of gastric GISTs among those classified as potentially malignant or malignant by the existing criteria. Majority of these tumors were large although mitotically inactive, placing them in the category of uncertain malignant potential. Clinical follow-up data for this group of GISTs suggests a less aggressive course of disease, with only 1 (8\%) of 13 analyzed cases having liver metastasis, but follow-up was relatively short in some cases. However, gastric GISTs with deletions in KIT-JM with similar clinical follow-up revealed metastatic disease in 13 (36\%) of 36 analyzed cases. More gastric GISTs with and without ITDs in the 3' KIT-JM should be evaluated to test the hypothesis that the presence of this mutation signifies a less aggressive clinical course. The rarity of these mutations in intestinal GISTs does not allow for a clinicopathological correlation.

Although the signaling consequences of ITDs in the 3' KIT-JM have not been studied in human GISTs, in vitro studies on canine mastocytoma cell lines have shown that these ITDs are associated with high constitutive phosphorylation of KIT protein $(37,41)$. Similar type of ITDs affecting the FMSrelated tyrosine kinase 3 (FLT3), another member of the type III receptor tyrosine kinase gene family, were found in human acute myelogenous leukemia $(42,43)$. Further in vitro studies using KIT constructs are necessary to verify their activating nature in human GIST. Also, the impact on the KITsignaling pathways by ITDs in the 3' KIT-JM has to be determined.

In summary, we have shown that ITDs in the 3' KIT-JM are rare. The majority of GISTs with these mutations are mitotically inactive tumors, predominantly occurring in the stomach, and seem to have a favorable course. The presence of this type of mutation may define a clinicopathological subset of gastric GISTs.

\section{REFERENCES}

1. Miettinen M, Majidi M, Lasota J. Pathology and diagnostic criteria of gastrointestinal stromal tumors (GISTs): a review. Eur J Cancer 2002;38 (Suppl):S39-51.

2. Nishida T, Hirota S. Biological and clinical review of stromal tumors in the gastrointestinal tract. Histol Histopathol 2000; 15:1293-301.

3. Kindblom LG, Remotti HE, Aldenborg F, et al. Gastrointestinal pacemaker cell tumor (GIPACT): gastrointestinal stromal tumors show phenotypic characteristic of the intestinal cells of Cajal. Am J Pathol 1998;152:1259-69.

4. Thuneberg L. Interstitial cells of Cajal: intestinal pacemaker cells? Adv Anat Embryol Cell Biol 1982;71:1-130.

5. Sanders KM. A case for interstitial cells of Cajal as pacemakers and mediators of neurotransmission in the gastrointestinal tract. Gastroenterology 1996;111:492-515.

6. Thomsen L, Robinson TL, Lee JCF, Farraway L, et al. Interstitial cell of Cajal generate a rhythmic pacemaker current. Nat Med 1998;4:848-51.

7. Koh SD, Sanders KM, Ward SM. Spontaneous electrical rhythmicity in cultured interstitial cells of Cajal from the murine small intestine. J Physiol (Lond) 1998;513:203-13.

8. Der-Silaphet T, Malysz J, Arsenault AL, et al. Interstitial cells of Cajal direct normal propulsive contractile activity in the small intestine. Gastroenterology 1998;114:724-36.

9. Ward SM, Morris G, Reese L, et al. Interstitial cells of Cajal mediate enteric inhibitory neurotransmission in the lower esophageal and pyloric sphincters. Gastroenterology 1998; 115:314-29.

10. Yarden Y, Kuang WS, Yang-Fend T, et al. Human protooncogene kit, a new cell surface-receptor tyrosine kinase for an unidentified ligand. EMBO J 1987;6:3341-51.

11. Williams DE, Eisenman J, Baird A, et al. Identification of a ligand for the c-kit proto-oncogene. Cell 1990;63:167-74.

12. Zsebo KM, Williams DA, Geissler EN, et al. Stem cell factor is encoded at the SI locus of the mouse and is ligand for the c-kit tyrosine kinase receptor. Cell 1990;63:214-24.

13. Vliagoftis H, Worobec AS, Metcalfe DD. The proto-oncogene c-kit and c-kit ligand in human disease. J Allergy Clin Immunol 1997;100:435-40.

14. Maeda H, Yamagata A, Nishikawa S, et al. Requirement of c-kit for development of intestinal pacemaker system. Development 1992;116:369-75.

15. Tsuura Y, Hiraki H, Watanabe K, et al. Preferential localization of c-kit product in tissue mast cells, basal cells of skin, epithelial cells of breast, small cell lung carcinoma and seminoma/dysgerminoma in human: immunohistochemical study of formalin-fixed, paraffin-embedded tissues. Virchows Arch 1994;424:135-41.

16. Longley BJ, Tyrrell L, Lu S-Z, Ma Y-S, Langley K, Ding T, et al. Somatic c-KIT activating mutation in urticaria pigmentosa and aggressive mastocytosis: establishment of clonality in a human mast cell neoplasm. Nat Genet 1996;12:312-4.

17. Gari M, Goodeve A, Wilson G, Winship P, Langabeer S, Linch $\mathrm{D}$, et al. C-kit protooncogene exon 8 in-frame deletion plus insertion mutations in acute myeloid leukemia. Br J Haematol 1999;105:894-900.

18. Nakata Y, Kimura A, Katoh O, Kawaishi K, Hyodo H, Abe K, et al. C-kit point mutation of extracellular domain in patients with myeloproliferative disorders. Br J Haematol 1995; 91:661-3.

19. Hongyo T, Li T, Syaifudin M, Baskar R, Ikeda H, Kanakura Y, et al. Specific c-kit mutations in sinonasal natural killer/T- 
cell lymphoma in China and Japan. Cancer Res 2000;60: 2345-7.

20. Tian Q, Frierson HF Jr, Krystal GW, Moskaluk CA. Activating c-kit gene mutations in human germ cell tumors. Am J Pathol 1999;154:1643-7.

21. Przygodzki RM, Hubbs AE, Zhao F-Q, O'Leary TJ. Primary mediastinal seminomas: evidence of single and multiple KIT mutations. Lab Invest 2002;82:1369-75.

22. Hirota S, Isozaki K, Moriyama $\mathrm{Y}$, et al. Gain-of-function mutations of c-kit in human gastrointestinal stromal tumors. Science 1998;279:577-80.

23. Ernst SI, Hubbs AE, Przygodzki RM, et al. KIT mutation portends poor prognosis in gastrointestinal stromal/smooth muscle tumors. Lab Invest 1998;78:1633-6.

24. Lasota J, Jasinski M, Sarlomo-Rikala M, et al. Mutations in exon 11 of c-kit occur preferentially in malignant versus benign gastrointestinal stromal tumors and do not occur in leiomyomas or leiomyosarcomas. Am J Pathol 1999;154:5360 .

25. Moskaluk CA, Tian Q, Marshall CR, Rumpel CA, Franquemont DW, Frierson HF Jr. Mutations of c-kit JM domain are found in a minority of human gastrointestinal stromal tumors. Oncogene 1999;18:1897-902.

26. Taniguchi M, Nishida T, Hirota S, et al. Effect of c-kit mutation on prognosis of gastrointestinal stromal tumors. Cancer Res 1999;59:4297-300.

27. Lux ML, Rubin BP, Biase TL, et al. KIT Extracellular and kinase domain mutations in gastrointestinal stromal tumors. Am J Pathol 2000;156:791-5.

28. Lasota J, Wozniak A, Sarlomo-Rikala M, et al. Mutations in exons 9 and 13 of KIT gene are rare events in gastrointestinal stromal tumors. A study of two hundred cases. Am J Pathol 2000;157:1091-5.

29. Rubin BP, Singer S, Tsao C, et al. KIT activation is a ubiquitous feature of gastrointestinal stromal tumors. Cancer Res 2001;61:8118-21.

30. Miettinen M, Furlong M, Sarlomo-Rikala M, et al. Gastrointestinal stromal tumors, intramural leiomyomas and leiomyosarcomas in the rectum and anus-a clinicopathologic, immunohistochemical and molecular genetic study of 144 cases. Am J Surg Pathol 2001;25:1121-33.

31. Wardelmann E, Neidt I, Bierhoff E, Speidel N, Manegold C, Fischer HP, et al. c-kit mutations in gastrointestinal stromal tumors occur preferentially in the spindle rather than in the epithelioid cell variant. Mod Pathol 2002;15:125-36.
32. Singer S, Rubin BP, Lux ML, Chen C-J, Demetri GD, Fletcher CDM, et al. Prognostic value of KIT mutation type, mitotic activity, and histological subtype in gastrointestinal stromal tumors. J Clin Oncol 2002;20:3898-905.

33. Demetri GD, von Mehren M, Blanke CD, van den Abbeele $\mathrm{AD}$, Eisenberg B, Roberts PJ, et al. Efficacy and safety of imatinib mesylate in advanced gastrointestinal stromal tumors. N Engl J Med 2002;347:472-80.

34. Miettinen M, Sarlomo-Rikala M, Lasota J. KIT expression in angiosarcomas and early fetal endothelial cells and lack of c-kit mutations in angiosarcoma. Mod Pathol 2000;13:53641.

35. Sakurai S, Fukasawa T, Chong JM, et al. C-kit gene abnormalities in gastrointestinal stromal tumors (tumors of interstitial cells of Cajal). Jpn J Cancer Res 1999;90:1321-8.

36. Fukasawa T, Chong JM, Sakurai S, Koshiishi N, Ikeno R, Tanaka A, et al. Allelic loss of $14 \mathrm{q}$ and 22q, NF2 mutation, and genetic instability occur independently of c-kit mutation in gastrointestinal stromal tumor. Jpn J Cancer Res 2000;91:1241-9.

37. London CA, Galli SJ, Yuuki T, Hu Z-Q, Helfand SC, Geissler EN. Spontaneous canine mast cell tumors express tandem duplications in the proto-oncogene $c$-kit. Exp Hematol 1999; 27:689-97.

38. Robinson TL, Sircar K, Hewlett BR, et al. Gastrointestinal stromal tumors may originate from a subset of CD34positive interstitial cells of Cajal. Am J Pathol 2000;156:115763.

39. Vanderwinden JM, Rumessen JJ, De Laet MH, et al. CD34+ cells in human intestine are fibroblast adjacent to, but distinct from, intestinal cells of Cajal. Lab Invest 1999;79:59-65.

40. Zemke D, Yamini B, Yuzbasiyan-Gurkan V. Mutations in the juxtamembrane domain of c-KIT are associated with higher grade mast cell tumors in dogs. Vet Pathol 2002;39:529-35.

41. Ma Y, Longley BJ, Wang X, Blount JL, Longley K, Caughey H. Clustering of activating mutations in $c$-KIT's juxtamembrane coding region in canine mast cell neoplasms. J Invest Dermatol 1999;112:165-70.

42. Nakao M, Yokota S, Iwai T, Kaneko H, Horiike S, Kashima K, et al. Internal tandem duplication of the flt3 gene found in acute myeloid leukemia. Leukemia 1996;10:1911-8.

43. Kiyoi H, Naoe T. FLT3 in human hematologic malignancies. Leuk Lymphoma 2002;43:1541-7. 